\title{
Estatus legal precario y condicionalidad en el acceso a derechos. Una aproximación a la regulación migratoria de Argentina y Canadá*
}

\author{
Precarious legal status and conditionality in the acces to rights. \\ An approach to migratory regulations from Argentina and Canada
}

\author{
Luis Eduardo Thayer Correa** \\ Facultad de Ciencias Sociales, Universidad Central de Chile \\ Fernanda Stang*** \\ Universidad Nacional de Córdoba \\ Cristóbal Abarca ${ }^{* * * *}$ \\ Fundación CREA
}

Recibido: 21 de enero de 2017. Aceptado: 1 de febrero de 2017

\section{Resumen}

Este estudio tiene por objetivo central comparar los marcos normativos vigentes que regulan la migración en Canadá y Argentina con el propósito de identificar en ellos las condiciones que inciden, ya sea para restringir o bien para retrasar el acceso a derechos. Para ello se compararon los cuerpos legales de ambos países en relación a sus fundamentos declarados, las condiciones para el acceso a los derechos, el tránsito entre categorías migratorias y la heterogeneidad de las mismas. Nuestra hipótesis de trabajo asume que los marcos normativos y los sistemas de visado/residencia más complejos, vale decir, aquellos que buscan sobrerregular las trayectorias de los migrantes, inciden en la creación de más alternativas para el retroceso en el acceso a los derechos, para la prolongación

Este artículo se inscribe en la ejecución de proyecto Fondecyt $\mathrm{N}^{\circ} 1140679$ y también ha contado con patrocinio del Departamento de Extranjería y Migración de Chile.

** Doctor en Sociología. Investigador de la Universidad Central de Chile, Facultad de Ciencias Sociales. Correo electrónico: luis.thayer@ucentral.cl

*** Doctoranda en Estudios Sociales de América Latina, Universidad Nacional de Córdoba, Argentina. Miembro del Observatorio de Políticas Migratorias de la Universidad Central de Chile. Correo electrónico: ferstang@yahoo. com.ar

**** Sociólogo de la Pontificia Universidad Católica de Chile e investigador de Fundación Crea. Correo electrónico: cristobalabarcabrown@gmail.com 
de la temporalidad y la eventual caída en la irregularidad. La pregunta que orientó este estudio buscó establecer qué consecuencias han traído para el acceso a los derechos de los migrantes los sistemas de visado/residencia vigentes en la institucionalidad migratoria de Argentina y Canadá. En términos metodológicos, la producción de información se basó en la sistematización de la normativa vigente en los dos países y en su análisis a partir de las evaluaciones realizadas desde la literatura especializada en cada uno de ellos. Se aplicó para ello el análisis de contenido de los cuerpos normativos. Adicionalmente se realizaron entrevistas a informantes claves para triangular los resultados y fuentes.

Palabras clave: estatus precario, migración, políticas migratorias.

\begin{abstract}
The objective of this study is to compare the existing regulatory frameworks migration in Canada and Argentina, with the purpose of identifying the conditions that affect access to or delaying access to rights. To this end, the legal frameworks of those countries were compared in relation to their principles, the conditions for access to rights, the restrictions between migratory categories and their heterogeneity. Our working hypothesis assumes that the more complex visa/residence systems are, the higher the impact on the production of alternatives for the retrogression in the access to rights, the prolongation of the temporality, and the eventual fall in the irregularity. In this sense, the question that leads this study seeks to establish what consequences have been brought to the access to the rights of migrants, the visa/residence systems in the migratory frameworks of Argentina and Canada. In methodological terms, the production of information was based on the systematization of the regulations in the two countries and their analysis based on the evaluations carried out by the specialized literature in both. It was addressed with content analysis. Key informants were also interviewed to triangulate the results and sources.
\end{abstract}

Keywords: precarious status, migration, rights, migratory policies. 


\section{La condicionalidad como expresión del estatus legal precario de los migrantes}

En un sentido normativo, la relación entre migrantes y ciudadanía es el resultado de un conjunto de condiciones legales e instrumentos administrativos que regulan un acceso restringido a los derechos (Sassen, 2010) ${ }^{1}$. Desde ese presupuesto, el objetivo de este estudio es dar cuenta de los mecanismos legales y administrativos con los cuales los Estados argentino y canadiense contribuyen a la producción de la categoría de migrante como un conjunto de condiciones que restringen la ciudadanía (Goldring y Landolt, 2013). Más específicamente, el interés residió en indagar cómo sus sistemas de visado y residencia ${ }^{2}$ contribuyen diferencialmente a generar condiciones para un mayor o menor acceso a los derechos y facilitar trayectorias migratorias estables y de acceso creciente o decreciente a la ciudadanía. El supuesto desde el que partimos es que los dos sistemas representan modelos distintos en cuanto a sus fundamentos declarados, pero también a la complejidad de los instrumentos para regular las trayectorias, y por lo tanto disímiles respecto de las condiciones que generan espacios para la irregularidad y el retroceso en el acceso a derechos ${ }^{3}$ (Wright, 2013). Al mismo tiempo, son modelos distintos en cuanto a la imposición de condiciones de admisibilidad, acceso a derechos (Novick, 2008) y garantías para transitar entre categorías migratorias. En este sentido, el modelo canadiense resulta más restrictivo en cuanto a las condiciones de admisibilidad y el acceso a derechos, y heterogéneo en lo relativo a la existencia de categorías migratorias, mientras que el argentino aparece en principio como garantista en cuanto al acceso a derechos y al tránsito entre categorías, pero complejo respecto de la heterogeneidad de las categorías migratorias.

Otro de los supuestos considerados, y de los desafíos analíticos de esta línea de estudio, deriva del hecho de que si bien la condición de migrante es antagónica a la de ciudadano

1 Se adopta aquí, como es obvio, una mirada estadocéntrica de la migración, un enfoque cuestionado, por ejemplo, por propuestas como la del movimiento No Border (<http://www.noborder.org/ $>$ ) o aproximaciones teóricas como la autonomía de las migraciones (por ejemplo, Mezzadra, 2012). Esta mirada implica, como señalaba Eduardo Domenech -académico de la Universidad Nacional de Córdoba- en la entrevista que le realizamos en el marco de este trabajo, una idea muy formal de la ciudadanía, puesto que en realidad esta se ejerce de hecho, no solamente en términos de reconocimiento del Estado (entrevista a Eduardo Domenech, 26 de octubre de 2016). Aunque concordamos en gran parte con estos posicionamientos, en la medida que este trabajo se limita al análisis normativo, excluye la consideración de las prácticas y representaciones en torno a los procesos de construcción de ciudadanía desde abajo por parte de los propios migrantes.

2 Se hace esta distinción porque en el caso argentino se diferencia entre visado (permiso de residencia otorgado desde el exterior) y residencia (permiso otorgado en el territorio nacional) (entrevista a Federico Agusti, director de Asuntos Internacionales y Sociales de la Dirección Nacional de Migraciones, 27 de octubre de 2016).

3 Es justamente esa la razón que justifica la elección de estos dos países para realizar el análisis comparativo. 
(Menjivar, 2006; Goldring, Berinstein y Bernhard, 2009), no es una categoría homogénea. Por el contrario, la categoría de "migrante" agrupa un conjunto de formas distintas de acceso restringido a los derechos que conforma un sistema de posiciones de "estatus legal precario" (Goldring y Landolt, 2013), o de formas de condicionalidad; una suerte de gradiente que va desde el extremo de la negación total de los derechos, representado por los migrantes indocumentados (Bernhard, Goldring, Young, Wilson y Berinstein, 2008), hasta la condición de extranjeros con permiso de residencia definitiva. Entre medio, cada Estado produce un rango de posiciones de ciudadanía restringida; un conjunto de in-between statuses que componen una "zona gris" (Menjivar, 2006) de posiciones diferenciadas. En tal sentido, la condición de migrante se configura como un sistema de posiciones definido por la existencia de alguno de los siguientes elementos: (a) falta de autorización de trabajo; (b) ausencia del derecho a residir de manera permanente en el país; (c) dependencia de los derechos propios respecto del derecho de una tercera persona para residir en el país; y (d) ausencia del acceso pleno a los derechos garantizados para los residentes permanentes nacionales y extranjeros (Menjivar, 2006). Es decir, la precariedad en el estatus legal de los migrantes se define por la institucionalización de la negación total o parcial de los derechos reconocidos a los ciudadanos nacionales. Esa heterogeneidad, que define las distintas formas de producción estatal de la condición de migrante, permite superar la concepción binaria con que habitualmente la literatura ha abordado el problema del acceso a los derechos de la población extranjera (Goldring et al., 2009), esto es, desde oposiciones bipolares como regularidad/irregularidad, legal/ ilegal o ciudadanía/no ciudadanía.

Adicionalmente, podemos señalar que la categoría "migrante", además de no ser homogénea, es dinámica, vale decir, supone que los sujetos siguen trayectorias a través de las distintas posiciones de estatus que impone la normativa y por las estrategias de adaptación a ellas que desarrollan los propios migrantes. A diferencia de lo que ha venido sosteniendo la literatura del campo hasta la década de 2000, este tránsito entre posiciones no implica necesariamente ascender linealmente en la "escalera de los derechos", sino al contrario; como se ha venido mostrando profusamente para el caso de la migración hacia América del Norte (Menjivar, 2006; Menjivar y Abrego, 2012; Goldring y Landolt, 2012, 2013; Goldring et al., 2009; Bernhard et al., 2008) y Europa del Sur (Calvita, 2007), implica además la posibilidad de retroceder en el sistema de estratificación de derechos (Bauböck, 2006) o perpetuarse en una posición supuestamente transitoria o temporal (Menjivar, 2006).

De manera que la noción de trayectoria que se asume aquí (Cachón, 1989) entra en tensión con la lectura lineal y ascendente con que parte de la literatura sobre migración 
y ciudadanía interpreta el proceso de "integración" de los migrantes a la esfera de los derechos (López, 2005). Una parte significativa de estos estudios están anclados en la mirada evolucionista que desarrolla T. H. Marshall (2001) en su obra clásica, que concibe el acceso de los migrantes a la ciudadanía como un proceso de ampliación creciente de derechos mediado por un sistema de regulaciones para ir atravesando sucesivas "puertas de entrada" a la sociedad (López, 2005). Aquí ponemos el foco justo en la cara opuesta: en aquellos elementos que inducen al cierre de las puertas, retrasan la posibilidad de atravesarlas, alargan el camino entre una y otra, o directamente invierten la dirección de las trayectorias, obligando a los migrantes a volver a cruzar las puertas que ya habían traspasado.

Partiendo de estos dos supuestos, esta investigación se organizó en base a dos hipótesis específicas. La primera plantea que el "estatus legal precario", incluyendo la "no ciudadanía" (Bernhard et al., 2008) que implica la irregularidad, son condiciones que el Estado contribuye a producir mediante el cuerpo normativo que regula el acceso de los migrantes a los derechos. En esta propuesta, el foco se pone principalmente en el análisis del sistema de visado/residencia, aunque se asume que el acceso a los derechos no depende exclusivamente de este, sino también de los documentos administrativos, instrumentos de política pública, ordenanzas municipales, instructivos, circulares sectoriales, entre otros, así como de las acciones y disposiciones de los funcionarios "de nivel de calle" que están en posición de garantizar o negar el acceso a los derechos. La segunda hipótesis plantea que el estatus legal precario no es un estado necesariamente transitorio, sino una condición que puede perpetuarse en las trayectorias migratorias, y que el sistema de visado/residencia es la institucionalidad central para superar ese estatus o para perpetuarlo. Estas trayectorias, entonces, no debieran ser entendidas en la lógica de ascenso creciente en la escala de derechos, sino como trayectorias de ascenso y descenso; de permanencia en el acceso restringido; y de caída en la no ciudadanía. Las nociones de "temporalidad permanente" o de "legalidad transicional" (liminal legality) que propone Menjivar (2006) permiten dar cuenta justamente de trayectorias en las que perdura el acceso restringido a los derechos. Se deriva de esta hipótesis el supuesto de que los migrantes pueden perder derechos independientemente de la situación en la que se hayan encontrado con anterioridad, y que por lo tanto la caída en la irregularidad y la "pérdida del estatus" pueden ocurrir como parte de la trayectoria, y no como suele suponerse (López, 2005), como el punto de partida de las trayectorias más precarias. A partir de estas hipótesis, en este estudio se ha buscado identificar las consecuencias desiguales que tienen los sistemas de visado/residencia de Canadá y Argentina en cuanto al acceso a los derechos de los migrantes y la definición de sus trayectorias ciudadanas. La elección de estos países responde, por una parte, a que ambas regulaciones son 
contemporáneas y se inspiran explícitamente en modelos distintos: la canadiense se funda en una lógica instrumental que antepone a la política migratoria los intereses del desarrollo y el bienestar nacional, mientras que la argentina declara estar fundamentada en los derechos humanos como principio rector. Además, la regulación argentina cuenta con procedimientos que permiten el tránsito entre categorías migratorias con mayor fluidez que la canadiense.

Considerando los objetivos de este estudio, se realizó un análisis descriptivo de la legislación migratoria vigente en los dos países. Se excluyeron de este análisis los elementos del marco regulatorio que aluden a la condición de refugiados, en primer lugar, debido a la necesidad de resguardar la viabilidad de este estudio inicial y exploratorio, y, en segundo término, pues el análisis de la condición de refugiados en el caso de Argentina responde a una regulación independiente de la referida a las migraciones. Al mismo tiempo, el análisis de la condición de refugiado implica asumir supuestos distintos a los considerados aquí, pues está regida por principios y condicionalidades diferentes de las que tocan a la población migrante. Requiere, por lo tanto, un análisis específico que incluya una referencia al marco de protección internacional de la población refugiada 4 .

El análisis de contenido de la información se realizó a partir del procesamiento de la normativa vigente en base a la definición de cuatro variables de caracterización. La primera, denominada "fundamentos", buscó identificar los principios de cada sistema, pues estos expresan las justificaciones políticas e ideológicas de cada regulación. La segunda, nombrada como "acceso a derechos", buscó comparar las garantías de derechos asociadas a cada permiso y las exclusiones que explícitamente se señalan en esa materia. Con la tercera variable, definida como “diversidad de categorías migratorias", se buscó analizar la heterogeneidad del sistema a partir de varias características: los distintos tipos de visa en función de conocer las condiciones que deben cumplirse para su otorgamiento, así como para la pérdida de la categoría asignada, y la duración de cada permiso. Eso último con el propósito de identificar la magnitud de la temporalidad esperada en términos normativos, un factor clave que, sin embargo, es necesario profundizar en el futuro, vinculándolo a los procedimientos administrativos, los costos y las restricciones de cada categoría ${ }^{5}$. La cuarta, que se denominó "tránsito entre

4 Para el caso de Canadá se revisó el "Immigration And Refugee Protect Act" de 2002, con las modificaciones hasta julio de 2015, y el "Immigration and Refugee Protection Regulations", de 2002. En el de Argentina se consideró la Ley de Migraciones (25.871), de 2003, y su Decreto Reglamentario N616/2010, de 2010.

5 A partir de estas variables se construyó una matriz de análisis que permitió ordenar la información de modo que fuese más abordable una aproximación comparativa. Esos cuadros se excluyeron deliberadamente de este texto por razones de espacio. 
visas", pretendió establecer cuáles son los posibles trayectos que permiten las distintas categorías migratorias definidas por el sistema de visado/residencia. Cabe señalar que en una segunda etapa de este trabajo se buscará complementar esta información con datos referidos a los procedimientos, los costos y la dependencia institucional del visado o su modificación. Dado el marco temporal de este trabajo, no fue posible incorporar en esta ocasión estas variables adicionales. Finalmente, como una forma de triangular la información y validar sus fuentes, se realizaron siete entrevistas a informantes clave, especializados en diversos aspectos de los marcos normativos de los países en cuestión.

\section{El estado de la discusión}

En términos teóricos, el problema que se aborda en este trabajo se inscribe en el campo de los estudios migratorios, específicamente en el marco analítico de los modos de incorporación, que pone de relieve el papel del Estado en la definición de las trayectorias migratorias (Portes y Böröcz, 1989; Portes y Rumbaut, 1990; Portes y DeWind, 2006). En esta línea, a partir de mediados de la década de 2000 se ha desarrollado una corriente aún incipiente, basada en estudios empíricos efectuados en Norteamérica y el sur de Europa, que ha formulado una crítica a los supuestos centrales asumidos previamente para comprender la relación entre migración y derechos, poniendo en relieve el papel del Estado como agente productor del estatus legal precario de los migrantes (Menjivar, 2006; Menjivar y Abrego, 2012; Goldring y Landolt, 2012, 2013; Goldring et al., 2009; Bernhard et al., 2008; Calvita, 2007). Esta línea de trabajo ha venido a cuestionar algunos de los supuestos asumidos por la literatura que se había desarrollado desde la década de 1990 sobre la relación entre migración y ciudadanía (Castles y Davidson, 2000; Castles, 1995, 2003, 2006; Bauböck, 2003, 2006; Faist y Gredes, 2006; Cachón, 2010; López, 2005; De Lucas, 2007; Solé, 2000; Carens, 2004).

En cuanto a lo primero, la tesis de que el Estado es determinante en las trayectorias de los migrantes se inscribe en un marco más amplio que plantea que el destino de las trayectorias migratorias depende de una combinación de tres factores: la receptividad del Estado, la acogida de la sociedad y la composición de clase y posición que ocupe el "colectivo" en el que el sujeto se incorpora en la estructura de la sociedad receptora (Portes

6 Las comillas en este término obedecen a una observación que realiza Sayad (1998), en el sentido de que no es posible hablar de una colectividad, o de una comunidad inmigrante en un determinado país, puesto que ello constituye una abstracción simple de un dato apriorístico. No por provenir del mismo país los migrantes representan una comunidad o una colectividad; esta es una percepción ingenua y etnocéntrica según la opinión del autor. 
y Böröcz, 1989; Portes y Rumbaut, 1990). Con ello se supera el enfoque individualista neoclásico, que asume que las trayectorias migratorias dependen de manera exclusiva de las competencias, estrategias y recursos de sujetos individuales (Portes y Böröcz, 1989). Esta investigación se ocupa exclusivamente de la variable estatal del problema, dejando por lo tanto en suspenso las otras dos.

Tradicionalmente, la literatura sobre migración y ciudadanía ha asumido, en sintonía con la obra de Marshall (2001), que los sujetos siguen una trayectoria secuencial y creciente de acceso a las distintas dimensiones de la ciudadanía (López, 2005). En este registro conceptual se interpreta, como se señala arriba, que los migrantes van atravesando sucesivas puertas de entrada a la ciudadanía. En la primera, los recién llegados accederían a los derechos civiles regulados por el control fronterizo, la extensión de visados y permisos de trabajo iniciales: la garantía de igualdad ante la ley, la protección legal contra la discriminación y el racismo, las políticas de apoyo inicial, entre otras medidas, formarían parte de esta etapa (López, 2005). La segunda "puerta de acceso" se asocia con "el conjunto de acciones que inciden en las condiciones de vida de los extranjeros y en sus posibilidades de inserción o incorporación a la sociedad de acogida" (López, 2005, p. 111). Esta dimensión se expresa en la normativa que regula el acceso a los derechos sociales: a los sistemas de salud y educación pública, a la vivienda, los incentivos a la formación de organizaciones de migrantes, las políticas que potencian la igualdad de oportunidades en el mercado laboral, la reagrupación familiar, el acceso a la vivienda, etc. Hacia fines de la década de 1990, a partir de la emergencia (conceptual) de las sociedades multiculturales (Zapata, 2009; Kymlicka, 1996), se incorpora en esta segunda etapa la intervención estatal orientada a consagrar los derechos culturales de las minorías migrantes o históricamente excluidas, como los pueblos originarios (Castles y Davidson, 2000). Finalmente, la tercera puerta de acceso regularía el reconocimiento de los derechos políticos y la participación de los migrantes en los procesos de configuración del poder.

Frente a esta interpretación lineal de las trayectorias migratorias han surgido cuestionamientos críticos en al menos tres sentidos. En primer lugar, se plantea que esta lectura desconoce que en la práctica muchas regulaciones migratorias inciden en una precarización de las trayectorias, en el sentido de que crean condiciones para la pérdida de derechos. La metáfora del "juego de escaleras y toboganes" (Goldring y Landolt, 2013) expresa esta situación, que pone en evidencia la naturaleza inestable del acceso a derechos por parte de los migrantes. Un segundo conjunto de críticas ha cuestionado la supuesta linealidad en el acceso a la ciudadanía como una trayectoria que culmina en los derechos políticos. Ello desconocería que el acceso a los derechos sociales y a las mismas oportunidades de acceso al bienestar de la población nativa habrían generado en 
muchos países receptores el hecho de que las comunidades migrantes pierdan interés por incorporarse en la comunidad política (Brubaker, 1989), situación que habría dado origen a la categoría de "semiciudadano" o denizen (Hammar, 1989; Castles, 2003) para aludir a los migrantes residentes de largo plazo que cuentan con acceso formal y sustantivo a todos los derechos, con excepción de los políticos (Layton-Henry, 1990).

Una tercera línea de críticas a la concepción lineal de las trayectorias migratorias apunta a que el acceso a los derechos políticos es antecedido por un acceso efectivo de los migrantes a los derechos sociales. Diversos trabajos muestran que obtener derechos políticos no presupone el acceso a los derechos sociales en igualdad de condiciones respecto de la población nativa (Hammar, 1989; Castles y Miller, 1993; Castles, 1995; Brubaker, 1989; Layton-Henry, 1990). A partir de esta última línea de críticas se ha puesto de relieve la discusión en torno a las prácticas institucionales y las relaciones sociales como una instancia en la que se afirman o tensionan los objetivos perseguidos por la regulación:

Es de todos sabido que la igualdad formal oculta con frecuencia unas grandes desigualdades cualitativas y que los derechos legales pueden tener connotaciones diferentes según el trato que dispensen los funcionarios e incluso los ciudadanos comunes a los titulares de esos derechos. (Carens, 2004, p. 410)

De este modo, las definiciones jurídicas que condicionan el acceso a los derechos se conciben más como el comienzo de la política migratoria que como su punto cúlmine (Brubacker, 1989).

Estas críticas vienen a complejizar la concepción de incorporación en la esfera política como un tránsito lineal conducente a la plena ciudadanía; asimismo, cuestionan la idea de que entre la ciudadanía y la no ciudadanía existe una frontera única que divide una bipolaridad (Menjivar, 2006; Goldring y Landolt, 2013). Sugieren, al contrario, que entre la ciudadanía plena y la no ciudadanía existe un sistema de fronteras permeables asentado en regulaciones formales y prácticas sociales que conformarían una zona gris de estatus intermedios, que a su vez tenderían a convertirse en una constante en las trayectorias migratorias, limitando el autorreconocimiento de los migrantes en la sociedad receptora y su sentido de pertenencia a esta.

Con este trasfondo teórico, el análisis de los modelos regulatorios de la migración apuntó a definir condiciones en dos dimensiones. Por una parte, las condiciones para la admisibilidad y el acceso al territorio; y por la otra, las condiciones para el acceso a los derechos y recursos sociales (servicios, bienes, capitales, espacios, etc.). Del cruce 
simplificado de ambos ejes, considerando en el eje 1, de la admisibilidad, sistemas abiertos o restrictivos, y en el eje 2, del acceso a derechos, modelos inclusivos y excluyentes, surgen cuatro tipos ideales o modelos para el análisis (Esquema $\mathrm{N}^{\circ} 1$ ). En primer lugar, un modelo abierto en cuanto a la admisibilidad e inclusivo en cuanto al acceso a derechos, cercano al sistema de regulación existente en la Unión Europea para los ciudadanos de países miembros o aquellas condiciones derivadas del acuerdo de residencia del Mercosur en América Latina. A nivel nacional, el modelo argentino podría ubicarse en una posición cercana a este registro.

Un segundo modelo surge del cruce de una política restrictiva en cuanto a la admisibilidad, pero inclusiva en cuanto al acceso a derechos y recursos sociales, como es el caso del sistema canadiense o de los países del sur de Europa, en los que predomina un fuerte control fronterizo para los ciudadanos extracomunitarios, pero existen garantías de acceso a derechos sociales basadas en el principio de los derechos humanos (Arango, 2004).

El tercer modelo surgiría de una política de frontera abierta y una regulación excluyente en cuanto al acceso a derechos. El caso chileno se encuadra en buena medida en este modelo, puesto que no cuenta, salvo excepciones (y prácticas arbitrarias en el control de frontera), con restricciones normativas para el acceso al territorio, pero existen instrumentos normativos que dificultan el acceso a la ciudadanía, como la visa sujeta a contrato.

Finalmente se encuentra el cuarto modelo, basado en condiciones de admisibilidad restrictivas y en una política excluyente en cuanto al acceso a derechos, lo que podría observarse en la política migratoria de los países del Golfo Pérsico o de la cuenca occidental del Pacífico (Arango, 2004). En estos se sumaría una estricta selectividad en el acceso a una intensa regulación de la temporalidad y el acceso restringido a los derechos. Un modelo que aplica también para la famosa política de trabajadores invitados impulsada por Alemania en las décadas de 1950 y 1960, y que actualmente tiene resonancia en países como Canadá o Nueva Zelandia. 
Esquema $\mathrm{N}^{\circ} 1$

Modelos regulatorios según condiciones de admisibilidad y de acceso a derechos

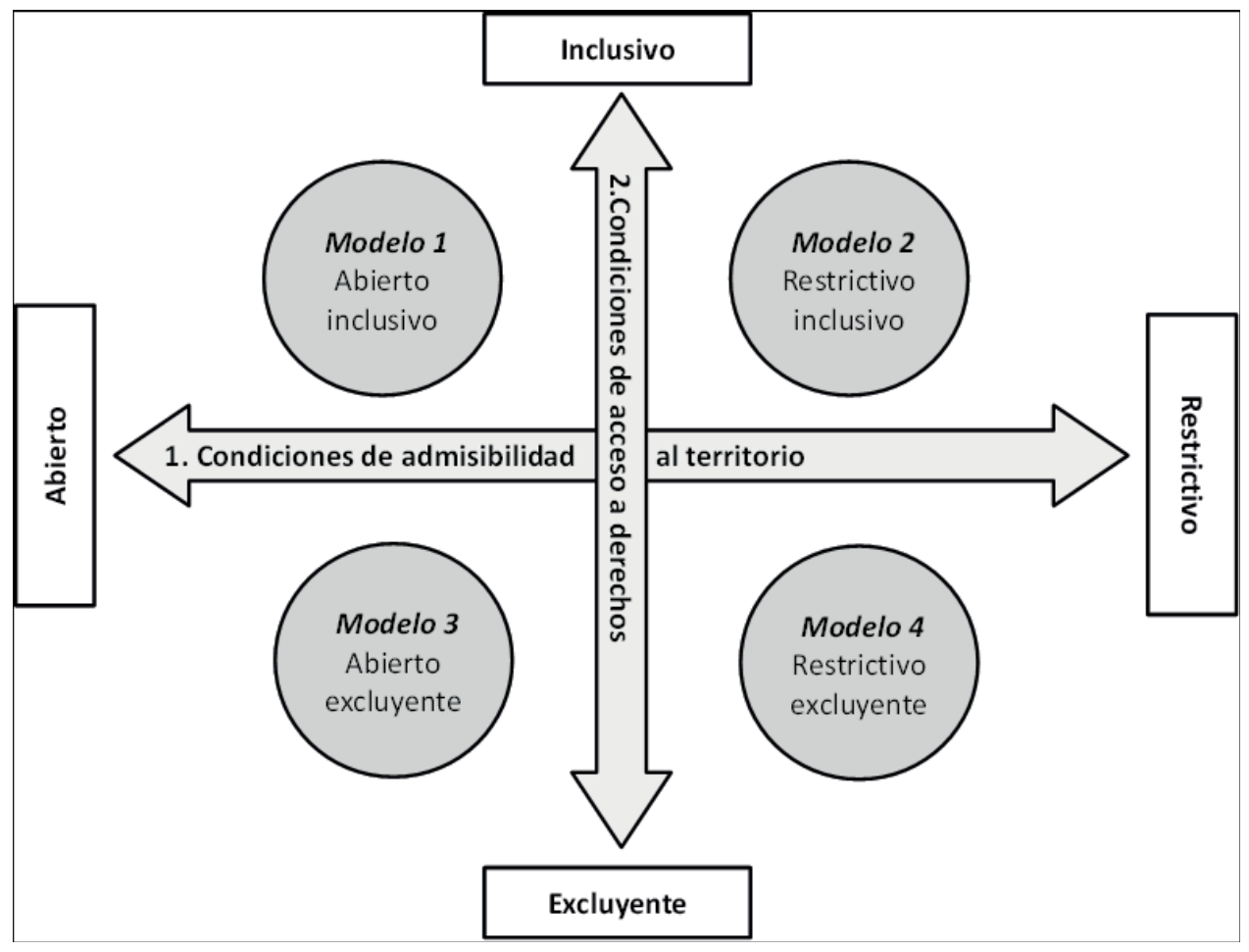

Fuente: elaboración propia.

Más allá de que estos modelos o "tipos ideales" difícilmente se encuentren en estado puro en la realidad, constituyen un instrumento analítico eficiente para comparar los sistemas de regulación de la migración vigentes. La estructura de este esquema bidimensional sirve de base para la definición de las variables y para el encuadre analítico de este trabajo.

Como se verá con mayor detalle al analizar los dos casos considerados según las variables definidas, de la revisión de la literatura producida en los dos países de referencia se desprende un predominio de las aproximaciones críticas a los modelos de visado y a la regulación migratoria. En Canadá esta crítica se focaliza esencialmente en el sistema de visas y regulación de la migración, así como en su incidencia en la creación de condiciones para la pérdida de derechos y la caída en la irregularidad. Vale decir, la crítica 
se dirige principalmente al sistema como un condicionante de la "producción legal de la ilegalidad". En el caso argentino la literatura orienta su crítica fundamentalmente a la inconsistencia entre la definición de la reforma migratoria realizada en $2003^{7}$ como un cuerpo normativo fundado en los derechos humanos, especialmente en el derecho a migrar, y en un contexto que tensiona (y cuestiona) esa definición, bien sea desde arriba, en base a acuerdos internacionales o por la conformación de un régimen global de control de las migraciones que permea los regímenes nacionales; o desde abajo, a partir de la organización social de la burocracia estatal encargada de poner en marcha la regulación.

\section{Aproximación a la normativa migratoria de Argentina y Canadá}

En esta sección se presenta el análisis comparado de la normativa migratoria de los dos países en relación a las cuatro variables descritas más arriba: los "fundamentos", que aluden a la definición de los principios que se encuentran en la base de los marcos regulatorios; luego se aborda la observación de la literatura en cuanto al acceso a derechos, tanto en relación a las condiciones de admisibilidad como a la trayectoria posterior; en tercer lugar se presenta una comparación en cuanto a la complejidad de los sistemas de visado/residencia; y finalmente la condicionalidad referida al tránsito entre categorías migratorias.

\section{Fundamentos}

Para el caso argentino, y considerando estrictamente el texto legal principal que regula actualmente la migración internacional en el país (Ley No25.871 y su reglamento), podría definirse este régimen regulatorio como un sistema garantista, sustentado en el enfoque de los derechos humanos. Esta observación alude a la vez a dos de las variables determinadas para este análisis: la definición sustantiva de la regulación y el reconocimiento normativo de derechos. Son numerosos los actores sociales que coinciden en este perfil garantista, tanto del ámbito académico como de las organizaciones e instituciones vinculadas al tema (Giustiniani, 2004; Novick, 2010; OIM, 2012; CELS, 2012). Efectivamente, entre

7 Se alude a la aprobación de la Ley de Migraciones º25.871 de 2003, que vino a reemplazar a la Ley General de Migraciones y Fomento de la Inmigración №22.439 de 1981, más conocida como Ley Videla, en referencia a la dictadura comandada por este general (1976-1983), en la que se originó. 
otros varios derechos, este instrumento jurídico reconoce explícitamente el derecho a migrar, en sentido amplio, como esencial e inalienable (artículo 4), algo que ni siquiera la propia Convención Internacional sobre la Protección de los Derechos de todos los Trabajadores Migratorios y de sus Familiares garantiza en esa forma, pues, en estricto rigor, este instrumento de Naciones Unidas solo reconoce el derecho a emigrar.

Se establece también, en el plano de los principios, una "igualdad de trato" entre nacionales y extranjeros respecto de sus derechos, pero a condición de que los segundos "satisfagan las condiciones establecidas para su ingreso y permanencia de acuerdo a las leyes vigentes" (artículo 5), y se asegura el acceso igualitario a los servicios sociales, los bienes públicos, la salud, la educación, la justicia, la seguridad social y el trabajo -en este caso, excepto que el extranjero se encuentre residiendo en "situación irregular", lo que, en definitiva, si no se da por obvia la "soberanía" del Estado para autorizar el ingreso de las personas a su territorio, contradice la idea de acceso igualitario ${ }^{8}$ - en las mismas condiciones de protección, amparo y derechos que los nacionales (artículo 6).

Sin embargo, se encuentran en la literatura algunos cuestionamientos respecto de la consistencia de este enfoque de derechos declarado en estos fundamentos. Una de las principales críticas cuestiona el supuesto cambio de paradigma que habría implicado la sanción de esta ley, esto es, desde la mirada securitizadora a la de los derechos (Domenech, 2009, 2013; Courtis y Pacecca, 2007)9. Desde este punto de vista se alude a un giro más bien retórico, especialmente en lo que se refiere a la materialización de este enfoque en una política migratoria. En esta línea, se argumenta que el discurso de los derechos

8 El artículo 52 impide realizar tareas remuneradas o lucrativas, por cuenta propia o en relación de dependencia, a los extranjeros admitidos como residentes temporarios, excepto que se tratara de la subcategoría de "trabajadores migrantes estacionales", o que hubiesen sido expresamente autorizados para ello por la Dirección Nacional de Migraciones. Y el artículo siguiente establece la misma prohibición respecto de los extranjeros que residieran “irregularmente". El artículo 55, en tanto, prohíbe a toda persona de existencia visible o ideal, ya sea pública o privada, el otorgamiento de trabajo a migrantes "irregulares" (igualmente, se prohíbe brindarles alojamiento), pero sin embargo se advierte que "en ningún modo se afectarán los derechos adquiridos por los extranjeros, como consecuencia de los trabajos ya realizados, cualquiera sea su condición migratoria” (artículo 56). A quien contraviniera la prohibición de dar trabajo se le impone una multa de 50 salarios mínimos, vitales y móviles por cada extranjero (artículo 59).

9 Como se señala en una nota al pie previa, la Ley 25.871, sancionada en diciembre de 2003 y promulgada en enero de 2004, vino a reemplazar a la Ley 22.439, o "Ley General de Migraciones y Fomento de la Inmigración" de 1981, norma que se sustentaba ideológicamente en la Doctrina de la Seguridad Nacional. Solo a título de ejemplo de este sustento, el artículo 95 de la derogada ley determinaba que el Ministerio del Interior podía expulsar del país a todo extranjero que "realizare en el país o en el exterior actividades que afecten la paz social, la seguridad nacional o el orden público de la república” (inciso b). Y entre los impedimentos de admisión mencionados por el reglamento de la ley, se anotaba el de "[r] egistrar antecedentes que hagan presumir que podría comprometer la seguridad o el orden público o la paz social” (artículo 22, inciso 6). 
humanos actuaría como una estrategia retórica legitimadora para lograr un control más efectivo de las migraciones. Esta estrategia sería parte de lo que se ha llamado las políticas de control con rostro humano (Domenech, 2013), es decir, el

universo de ideas y prácticas que, enmarcadas en el discurso de los derechos humanos como fuente de legitimación, persiguen la misma finalidad que las políticas más abiertamente restrictivas, prometiendo ser más eficaces en la consecución de su objetivo: controlar los flujos migratorios internacionales (Domenech, 2013, p. 121).

En cuanto al caso de Canadá, la normativa vigente desde 2002 consagra la migración como un vector del desarrollo y del bienestar de los ciudadanos canadienses; en este sentido, es un cuerpo normativo que se fundamenta en una mirada instrumental de los flujos migratorios. Con ello, la normativa mantiene el espíritu que poseían marcadamente las regulaciones anteriores, de 1952 y 1976 (Simmons, 2010). Sin embargo, en el Acta de 2002 este enfoque convive con el fundamento humanitario que define la política de acogida para los refugiados. A diferencia de lo que ocurre con la legislación argentina, en la que se separan la ley de migraciones y la que regula la situación de los refugiados ${ }^{10}$, en el caso canadiense, el acta de 2002 reúne ambas definiciones. Esto forma parte de la complejidad aludida de la normativa canadiense. Esta complejidad está además sujeta, en gran medida, a la discrecionalidad de la autoridad migratoria para modificar los criterios de admisibilidad, las condiciones para la permanencia, la ponderación de los puntos en la asignación de los requisitos para el otorgamiento de visas o incluso el cambio de las categorías migratorias (op. cit.). En este sentido, el espíritu de una regulación fundamentada en las necesidades del desarrollo económico queda expresado en la competencia de la autoridad para modificar los criterios según la contingencia del ciclo económico. Esto revela la significativa presencia que tiene la inspiración instrumental por sobre el enfoque de derechos de este marco normativo.

10 En el caso argentino, la ley de migraciones contempla la categoría de "asilados y refugiados" tanto entre los tipos de residencia temporal como permanente, pero remite a la norma que regula específicamente el tema, a saber, la Ley N²6.165, o Ley General de Reconocimiento y Protección al Refugiado, de 2006. 


\section{Garantía y acceso a derechos}

Respecto de esta dimensión de análisis, en el caso de la regulación argentina existe una declaración garantista, en el sentido de que contempla que en ningún caso la "irregularidad migratoria" del extranjero podrá impedirle su admisión en el sistema educativo, tanto público como privado y en todos los niveles (artículo 7), o su acceso a la salud, la asistencia social o la atención sanitaria (artículo 8). Al mismo tiempo, hay un reconocimiento explícito del derecho a ser informado sobre prerrogativas, obligaciones, requisitos de admisión, permanencia e ingreso o cualquier otra cuestión que le permita o facilite el cumplimiento de formalidades; así como también de la responsabilidad del Estado de proveer adecuadamente esa información. También se abre una puerta legal para el reconocimiento explícito de derechos políticos al sostenerse que

[1]a República Argentina facilitará, de conformidad con la legislación nacional y provincial en la materia, la consulta o participación de los extranjeros en las decisiones relativas a la vida pública y a la administración de las comunidades locales donde residan (artículo 11) $)^{11}$

Y se señala como un cambio significativo que supuso esta norma la incorporación del derecho al debido proceso en situaciones de detención y expulsión (artículos 61 y 70).

Aun así, en la literatura se exponen algunas objeciones que apuntan a la eficacia vinculada al perfil garantista declarado en estos fundamentos -además de los cuestionamientos sustantivos que señalamos en el apartado anterior. Uno de estos puntos de objeción (CELS, 2012) señala que si bien la regulación vigente desde 2003 consagra la migración como derecho humano, la existencia de deficiencias burocráticas perjudica la situación jurídica de los migrantes: fallas en el diseño de políticas de regularización, uso de diversos criterios interpretativos para analizar los expedientes migratorios y falta de consideración de antecedentes familiares o de arraigo en trámites de expulsión. Se señala en este sentido que existe una falta de implementación efectiva y una interpretación incorrecta de la normativa vigente. En la misma línea, se alude al problema de la inconsistencia entre la ley de migraciones y otros cuerpos normativos, que redundaría en la negación de un acceso igualitario a la seguridad social por la vigencia de otras normas que no se han derogado o no se ajustan a lo que establece la ley de migraciones. También se identifican otros obstáculos que afectan el acceso a los derechos de la población migrante, como

11 De hecho, en numerosas jurisdicciones los migrantes tienen acceso al voto para la elección de diversas autoridades (por tratarse de un régimen federal, el reconocimiento y alcance de este derecho varía según las provincias, que constituyen la división político-administrativa mayor de la organización político-administrativa del país). 
la ausencia de implementación de la residencia para trabajadores migrantes por cuenta propia, un asunto en el que coinciden otros autores (Courtis y Pacecca, 2007), además de los informantes claves entrevistados ${ }^{12}$, y que afecta especialmente a los migrantes extraMercosur ${ }^{13}$.

El trabajo de Novick $(2008,2010)$, que considera la producción normativa del Estado respecto de las migraciones desde una perspectiva histórica, valora la consideración explícita del derecho a migrar en la legislación; sin embargo, alude a la persistencia de una precariedad ciudadana basada en la institucionalización de prácticas de discriminación y explotación hacia los migrantes en el país, además de persecución y maltrato. Respecto de esto, se plantea que

los cambios en la legislación no se reflejan mecánicamente en los actores sociales que deben aplicar cotidianamente esas normas. Por el contrario, décadas de ideología autoritaria influyen en las contradicciones que a diario ocurren entre lo normado por la ley y las prácticas de la política (Novick, 2010).

La autora concluye que, en el nuevo escenario, la política migratoria se ha vuelto más compleja no solo por la diversificación de las procedencias de los migrantes y por las reacciones de muchos funcionarios a contramano del espíritu fundante de la ley, sino también porque en este cuerpo normativo los migrantes provenientes de algunos países como China o Corea han sido perjudicados por el régimen de residencia que emana de ella.

En este punto reside uno de los principales cuestionamientos actuales a la normativa vigente en Argentina: la dificultad que enfrentan los migrantes de ciertos orígenes nacionales extra-Mercosur para acceder a la regularidad y, por esa vía, al reconocimiento de derechos. La consideración específica de los migrantes mercosureños en la ley ${ }^{14}$ se

12 Entrevista a Verónica Jaramillo, Buenos Aires, 1 de noviembre de 2016.

13 Como se sostiene en un informe reciente del CELS: "Está claro que la Convención otorga a la categoría de trabajador migratorio un contenido amplio, que incluye las distintas realidades sociales que podrían determinar flujos migratorios, entre las cuales se sitúa como la matriz la realización de una actividad remunerada. Sin embargo, en la práctica, es imposible iniciar un trámite de residencia bajo esta categoría y no existe información al público acerca de esta norma, pues solamente se acepta a aquellas personas empleadas con contrato formal de trabajo -'en relación de dependencia"' (CELS, 2016).

14 Entre las subcategorías consideradas como "residentes temporarios" se incluyen los "[c]iudadanos nativos de Estados Parte del MERCOSUR, Chile y Bolivia, con autorización para permanecer en el país por dos (2) años, prorrogables con entradas y salidas múltiples" (artículo 23, inciso 1). Esa permanencia habilita luego a la obtención de la residencia permanente por arraigo (artículo 22, inciso c). 
señaló en un principio como uno de los dos elementos claves en la ruptura que la norma significó, junto a la inclusión de la perspectiva de los derechos humanos y al abandono de la doctrina de la seguridad nacional vehiculizada por la norma anterior. Este aspecto, aludido en la literatura como la incorporación de la noción de "ciudadanía comunitaria", o también como "regionalización", supuso un reconocimiento explícito de los principales flujos migratorios actuales (Domenech, 2007; Courtis y Pacecca, 2007). Tanto la literatura sobre el tema como varios de los entrevistados para este estudio ${ }^{15}$ aluden a la situación de grupos específicos de migrantes que enfrentan dificultades muchas veces insalvables para acceder a la regularidad ${ }^{16}$, debido a lo que se denomina "causas impedientes" (García, 2013): ya sea porque no caben bajo ninguno de los criterios migratorios establecidos en la ley, como en los casos de los dominicanos ${ }^{17}$ y senegaleses, o los chinos, porque no logran reunir los requisitos para regularizar su situación, pues ingresaron al territorio por pasos no habilitados, como le ocurre en buena medida a los senegaleses (Nejamkis y Álvarez Nievas, 2012), o por la existencia de antecedentes penales (García, 2013).

Sobre esta última situación específica, Acosta Arcarazo y Feline Freier (2015) proponen un interesante análisis. Los autores sostienen que el derecho a migrar, reconocido por la ley argentina, puede entenderse de dos formas: como una obligación del Estado de proporcionar vías de regularización y como derecho individual a disponer de un plazo para intentar regularizarse. Sin embargo, aquellos que no han ingresado de manera regular no pueden materializar ese derecho. Esa excepción no afectaría a los migrantes mercosureños ni a los de países de la OCDE, que no deben pagar visas para ingresar. Por lo tanto, a quienes afectaría principalmente esta medida es a los migrantes sur-sur que provienen de África, Asia y el Caribe. Los casos de senegaleses y dominicanos ilustran muy bien esta situación, que habilita a los autores a hablar de la reciente política de inmigración de la Argentina en particular y de América del Sur en general (también se analizan en su trabajo los casos de Brasil y Ecuador), como la paradoja de una política de inmigración inversa (es decir, de apertura en el discurso pero restrictiva en la práctica, al contrario de lo que ocurriría en Europa y Estados Unidos), escenario al que aluden como "liberalismo populista" sudamericano en la esfera de la migración.

15 Entrevista a Lila García y Agostina Hernández, investigadoras de la Universidad Nacional de Mar del Plata y la Universidad Nacional de Lanús, respectivamente, 28 de octubre de 2016; entrevista a Verónica Jaramillo, investigadora del CELS, 1 de noviembre de 2016.

16 Y que son víctimas de abusos de diverso tipo por esta dificultad. Véase, por ejemplo, el caso de tres ciudadanos chinos retenidos por 150 días en la localidad de Rafaela, provincia de Santa Fe, relatado en un informe reciente del CELS (2016).

17 Al igual que en el caso de Chile, a los ciudadanos dominicanos se les exige una visa consular para ingresar al país. 
En relación al caso de Canadá, la literatura se organiza en torno a un eje aglutinador, que es el sistema normativo como productor de la irregularidad o la ilegalidad migratoria ${ }^{18}$. A pesar de que algunos trabajos reconocen que aún es incipiente el análisis de la irregularidad en el país (Ellis, 2015), la investigación está orientada hacia el estudio de la producción normativa del "estatus legal precario" (Goldring et al., 2009). En efecto, el material disponible en torno a la discusión sobre los indocumentados o no-ciudadanos en el caso de Canadá ha reconocido a modo de consenso que existiría una producción de irregularidad por parte de la institucionalidad pública (De Génova, 2002). En esta línea, se ha buscado mostrar cómo la política migratoria canadiense proporciona diferentes vías de entrada autorizada que inciden en una ruptura de la concepción binaria de las categorías migratorias como legal/ilegal, poniendo de relieve el sistema de estratificación que descansa sobre la noción de "estado precario", el que daría cuenta de una importante variabilidad de situaciones de ilegalidad (De Génova, 2002).

A partir de esto, la literatura se ha enfocado en estudiar el marco legal de la institucionalidad migratoria canadiense (Crépeau y Nakache, 2006) y los modelos de ciudadanía (Bloemraad, 2016). Junto con ello, se han abordado las implicancias de la indocumentación sobre el acceso a servicios sociales como la salud (Magalhaes, Carrasco y Gastaldo, 2010). Algunas autoras han puesto sus cartas en el marco legal internacional y los derechos humanos; el trabajo de Basok y Carrasco (2010) ilustra en esta línea cómo sujetos migrantes politizados tensionan el marco normativo local, apelando al marco internacional de los derechos humanos, tensión que se traslada al poder judicial, quedando los jueces como árbitros decisivos para dirimir entre el reconocimiento del derecho internacional o del marco jurídico nacional como fundamento para el reconocimiento de los migrantes.

En esta misma línea se ha abierto una senda de análisis respecto de los efectos del estatus legal precario sobre los sujetos. Aquí se ha abordado el impacto que el estatus legal precario de uno de los integrantes de la familia tiene sobre el conjunto del núcleo familiar (Bernhard et al., 2008); o, como analizan Rajkumar, Berkowitz, Vosko, Preston y Latham (2012), las consecuencias que tiene la temporalidad sobre la seguridad, el trabajo y la vida económica de los migrantes (DeVoretz y Pivnenko, 2005). Uno de los

18 Sin desconocer las posturas dentro del campo de las migraciones que abogan por el uso del término "irregularidad" en reemplazo del de "ilegalidad", sosteniendo que no se puede considerar ilegal una contravención administrativa, somos partidarios del uso de la idea de "ilegalidad" a partir de los efectos que tiene sobre el migrante esta situación de construcción legal de la ilegalidad desde el Estado (De Génova, 2002), o desde la mirada de Foucault, la concepción de la ley como "un procedimiento por medio del cual se gestionan diferentes órdenes de ilegalismos" (Foucault, 1995, pp. v-vi). 
elementos significativos que aporta esta línea para nuestra investigación es la noción de "temporalidad permanente" (Rajkumar et al., 2012) como una condición derivada de un marco regulatorio que impone obstáculos para la obtención de la residencia permanente. Por último, en relación a la condicionalidad en el acceso a los derechos, la literatura canadiense ha abordado prácticas como los "exámenes de integración" que deben rendir los migrantes para optar a la ciudadanía (Rajkumar et al., 2012).

En cuanto al crecimiento de la migración temporal en relación a la permanente, la literatura ha dado cuenta de que la primera ha venido ganando terreno desde mediados de la década de 1990 (Basok y Piper, 2012; Preibisch, 2004), debido esencialmente a la creación de programas especiales para trabajadores de temporada. La evaluación que se realiza de este crecimiento apunta a destacar que la política migratoria ha contribuido a expandir un tipo de persona que vive y trabaja en Canadá sin tener acceso pleno a la ciudadanía ni a los derechos laborales (Goldring, et al. 2009; Goldring y Landolt, 2013), lo que se habría convertido en uno de los pilares de un sistema de jerarquización en el acceso a derechos en la sociedad canadiense: "Este análisis ha puesto luz sobre asuntos cruciales respecto de la ciudadanía, la inclusión y la sociedad canadiense, por ejemplo mostrando que los residentes temporales de largo alcance (long term teporary residents) carecen de muchos derechos que disfrutan otros residentes" (Goldring et al., 2009, p. 25).

\section{Diversidad de categorías migratorias}

La literatura relativa al caso argentino es crítica en cuanto a la complejidad del sistema de residencia, aunque es preciso decir que son muy pocos los trabajos que aluden de alguna manera a esta dimensión específica. A pesar de que en la norma existe una aparente simplificación del régimen a partir de tres grandes categorías (residentes transitorios, temporarios y permanentes), lo cierto es que hay una multiplicación de subcategorías que lo complejiza. Entre la norma y el reglamento se contabilizan 27 subcategorías para los residentes transitorios, temporarios y permanentes, e incluso la propia autoridad migratoria define la categoría contemplada en el artículo $24 \mathrm{~h}$, de "residente temporario especial", como un código abierto que permite la creación de nuevas subcategorías ${ }^{19}$. Como se ha señalado, varios de los académicos y entrevistados cuestionan esta diversificación

19 Entrevista con Federico Agusti, director de Asuntos Internacionales y Sociales de la Dirección Nacional de Migraciones, 27 de octubre de 2016. 
de categorías ${ }^{20}$ y fragmentación de derechos como un aspecto negativo de la norma, y en efecto es posible preguntarse en qué medida esta multiplicación no representa un obstáculo real al reconocimiento del derecho a migrar declarado en la misma ley. ¿En qué forma contribuye a garantizar este derecho una proliferación de motivos legitimados para el ingreso que siempre deja razones sin contemplar? La situación específica de algunos grupos nacionales, como chinos, senegaleses y dominicanos, aludida en el apartado anterior, abona la existencia de esta "contradicción".

Contribuye con esta sospecha fundada sobre la intencionalidad (no subjetiva) de un reconocimiento más expedito del derecho a migrar para un tipo de migrante cuyo ingreso y permanencia se considera deseable, y por el contrario, una obstaculización de este reconocimiento para el que no, el análisis más específico de las categorías contempladas en la normativa. Por ejemplo, de las catorce subcategorías enumeradas en el caso de la residencia temporal, ocho pertenecen a figuras de migrantes sobre los que es dable pensar que cuentan con solvencia económica para sustentar su vida en el país (rentista, pensionado, inversionista, científico y personal especializado, deportista y artista, religioso, académico y estudiante); otra es la subcategoría abierta a la que hacíamos alusión, disponible para situaciones específicas que se quiera contemplar (especial), tres pueden ubicarse bajo la idea de las razones humanitarias (una que lleva precisamente ese nombre, más la de asilado y refugiado, y la de paciente en tratamiento médico), y finalmente están el trabajador migrante y la subcategoría de nacionalidad, que contempla el caso de los migrantes de países miembros del Mercosur ampliado.

Por su parte, el marco normativo vigente desde 2002 en Canadá -la Immigration and Refugee Protection Act- ha encontrado valoraciones positivas desde el punto de vista de su complejidad y alcance regulador; es decir, es una legislación que pretende abarcar una muy vasta variedad de categorías migratorias, las que se organizan en dos grandes dimensiones o condiciones de residencia: la de residentes temporales y la de residentes permanentes. En términos generales, a la valoración de la complejidad y sofisticación de la regulación canadiense se contrapone una crítica que apunta a señalar que, incluso respecto de la legislación anterior, resulta sustantivamente más restrictiva en cuanto al acceso de los migrantes al territorio, pero también a los derechos (Lowry, 2002).

20 Por ejemplo, Courtis y Pacecca (2007); entrevista a Lila García y Agostina Hernández, 28 de octubre de 2016. Es preciso tener en cuenta además que esta diversificación se traduce en una complejidad de trámites que dificultan materialmente el acceso a la regularidad. En paralelo, es necesario considerar que esta proliferación tiene a su vez una contracara: la no habilitación de otras posibles categorías que facilitarían el acceso a determinados grupos de migrantes, como la de trabajador sin relación de dependencia, aludida en párrafos previos, lo que hablaría de una intencionalidad en el funcionamiento de este mecanismo. 
La categoría de residentes permanentes a la que se puede acceder en Canadá distingue tres tipos: los migrantes económicos (economic class), los familiares o acompañantes de titulares (family class) y las personas protegidas (protected persons) por motivos humanitarios. La primera incluye a los trabajadores calificados o a aquellos que tanto a nivel federal como provincial se consideran necesarios para el desarrollo de la economía, como es el caso de los trabajadores del sector de los cuidados o los migrantes empresarios. En la segunda categoría se considera a la familia inmediata del migrante: hijos, parejas, padres (abuelos de los hijos), etc. En la tercera se contempla a aquellos que son reconocidos como refugiados en virtud de la convención específica de las Naciones Unidas (sobre el Estatuto de los Refugiados). Desde inicios de 2002 hasta la fecha, la categoría que más ha crecido es la de migrantes económicos, lo que da cuenta del perfil migratorio y los énfasis de la política canadiense.

Por su parte, la residencia temporal se divide en cuatro grandes categorías: la de trabajadores extranjeros, la de estudiantes, los casos humanitarios (como solicitantes de asilo en proceso) y finalmente una cuarta categoría de "otros", en la que entran aquellos migrantes que no pueden ser categorizados en alguna de las otras tres clases. A diferencia de las otras tres categorías, la de trabajadores extranjeros se subdivide en un número importante de subcategorías, algunas de las cuales están definidas por programas específicos, como el que busca atraer a trabajadores temporales para la agricultura, para el servicio doméstico y los cuidados, o el programa para trabajadores altamente calificados. El crecimiento de la demanda de trabajadores extranjeros para la construcción y la industria petrolera también ha activado programas orientados a cubrir esta necesidad específica de mano de obra (Goldring et al., 2009). En términos generales, el crecimiento de la migración temporal en Canadá se ha dado esencialmente debido a la sostenida llegada de trabajadores temporales y de estudiantes.

\section{Tránsito entre visas}

En cuanto a esta dimensión del análisis, en términos comparativos podría decirse que en el caso de Argentina hay una significativa fluidez entre categorías dentro de la complejidad del sistema. En efecto, los obstáculos están puestos más bien en la posibilidad de acceso al camino de la regularidad para ciertas categorías no contempladas o situaciones determinadas (como el ingreso por un paso no habilitado), pero no especialmente en este tránsito entre categorías, ya sea por cambios en las razones que "legitiman" la presencia/estancia o por criterios de temporalidad. En definitiva, y aunque mucho se 
alude a este gran paraguas que ha habilitado este marco normativo, al facilitar el acceso a la regularidad para todos los migrantes provenientes del Mercosur ampliado por la sola razón de su nacionalidad, si se va más allá de la pura observación cuantitativa ${ }^{21}$, puede concluirse que el sistema argentino es bastante menos abierto en términos de condiciones de admisibilidad que de acceso a derechos, aunque por supuesto, también en términos comparativos, esas condiciones de admisibilidad puedan ser bastante más abiertas que las de muchos otros países.

De todos modos, varios de los informantes claves entrevistados aludieron a algunas disposiciones y acciones administrativas, adoptadas con posterioridad a la aprobación de la normativa migratoria principal, y que se revelan como mecanismos que buscarían poner restricciones a esta fluidez en el tránsito entre categorías de residencia, o bien a las estrategias a las que recurren los migrantes (especialmente los extra-Mercosur) para sortear los obstáculos específicos para la regularidad que enfrentan.

Aunque el análisis que se realiza en este artículo ha excluido este tipo de disposiciones y prácticas (por una decisión metodológica), vale la pena su mención. Una de estas medidas es la Disposición de la Dirección Nacional de Migración (DNM) 4362/2014 del 4/11/2014, "Procedimiento para la resolución de casos sobre sospecha fundada en la subcategoría turista", más conocida como la disposición del "falso turista". Este instrumento estipula la documentación que debe requerir el agente de frontera a la persona que pretendiere ingresar al territorio nacional "cuando hubiese duda respecto de la real intención del extranjero, en tanto que esta pudiera diferir del propósito de turismo". Evidentemente, la medida se relaciona con el hecho de que el ingreso como turista es generalmente el primer escalón para luego acceder a otra categoría de residencia dentro del país, en la medida en que no hay restricciones para este tránsito categorial -excepto el pago de un monto de dinero. Otra de las acciones emprendidas tiene que ver con la intención de detectar el "matrimonio fraude a la ley"22, estrategia utilizada en buena medida por los migrantes dominicanos y que se relaciona con la posibilidad de acceder a una residencia permanente a través del vínculo conyugal con un argentino nativo, naturalizado o por opción, o bien con un residente permanente.

En cuanto al caso canadiense, al ser más extensa la literatura, lo son también las críticas expresadas en ella. Una de las principales observaciones que se realiza al sistema canadiense como un marco que incentiva la precariedad se dirige principalmente al principio de separación de las categorías temporales y las permanentes, declarado

${ }^{21} \quad$ Más del 80\% de la población migrante que residía en el país en 2010 provenía de estos países (OIM, 2012).

22 Entrevista a Lila García y Agostina Hernández, 28 de octubre de 2016. 
en la definición misma del sistema. En este sentido, y con excepción del caso de los trabajadores temporales sujetos al programa para empleos en cuidados (Live in Care Workers Programme), quienes ingresan a través de un permiso de trabajo temporal no pueden transitar hacia un permiso de residencia permanente (Goldring et al., 2009). De manera que, en este caso, la segmentación normativa de categorías migratorias que institucionaliza la ley incentiva por una parte la llegada de trabajadores, a la vez que restringe severamente la permanencia de esos trabajadores en condiciones de acceso pleno a derechos en igualdad de condiciones que los otros trabajadores.

En relación a la separación de las grandes categorías migratorias entre residentes temporales y definitivos, es necesario añadir que la definición de ambas categorías como mutuamente excluyentes contribuye a que incluso aquellos trabajadores que pueden transitar a la residencia definitiva (trabajadores de cuidados) encuentren dificultades para alcanzar el estatus definitivo:

Por definición, el estatus de trabajador temporal significa que no es un residente permanente, carece de derechos y no es completamente miembro de la sociedad. Además, en la mayoría de los casos los residentes temporales nunca serán elegibles para convertirse en definitivos. (Goldring et al., 2009, p. 32; traducción propia)

Este condicionamiento de la residencia a la "temporalidad permanente" constituye una puerta de entrada al mercado de trabajo, que es en sí misma precaria, pues sujeta la residencia a un contrato con un empleador específico, pero además supone una proyección en el tiempo fuertemente orientada a la irregularidad (Arat-Koc, 1997). Este diagnóstico indica que la voluntad estatal de regular completamente el destino de los trabajadores extranjeros con este tipo de instrumentos que institucionalizan la restricción a la movilidad en la escala de derechos tiende a fracasar en su objetivo, incluso en sociedades desarrolladas, ordenadas, con instituciones sólidas y controladas, como es el caso canadiense.

Un segundo factor, identificado como incentivo a la pérdida de derechos o la caída en la irregularidad, tiene que ver con la condición de acompañante o la sujeción de los propios derechos a la titularidad de un tercero. En estos casos, cuando la relación termina antes que el o la acompañante pueda acceder al permiso de residencia definitiva, el proceso de postulación para el acompañante se anula, perdiendo la posibilidad de salir de la condición temporal. Además de incidir en la precarización de la condición de estos migrantes, esto podría tener un efecto negativo desde el punto de vista de las relaciones de género, toda vez que las acompañantes sean mujeres, y cuyos derechos queden sujetos 
a la condición del titular hombre, tal como lo mostró la investigación realizada por Latin American Coalition to End Violence Against Women and Children (LACEV, 2000), en la que se revelan los abusos a los que están expuestas las mujeres cuyo acceso a la residencia permanente está sujeto al patrocinio de la pareja masculina.

Una tercera vía de acceso a la precariedad en Canadá se relaciona con la transición de los solicitantes de refugio que tramitan su solicitud estando en el país. Durante el proceso, que puede durar varios meses o incluso años, los solicitantes acceden a un permiso de trabajo temporal provisorio que incide en que algunos empleadores eviten contratarlos, lo que los expone a una situación de precariedad, aun cuando posean un permiso de trabajo. Esta situación pone en evidencia la incidencia que puede tener la dimensión administrativa en la producción de la precariedad: la demora en los procedimientos y la regulación de la trayectoria mediante permisos provisorios pone a los titulares de estos permisos frente a potenciales vulneraciones de los derechos que justamente se pretende garantizar con la institucionalización de la condición provisoria. La formalización de números especiales como marcas de estos permisos, como el nueve al inicio de las tarjetas de la seguridad social de estos solicitantes, permite identificarlos, facilitando su estigmatización. Una situación de mayor precariedad se genera en aquellas personas cuya condición de refugiadas es rechazada o son consideradas no elegibles. En ambos casos los solicitantes quedan en situación de deportación; sin embargo, el Estado canadiense no cuenta con los recursos suficientes para ejecutar las órdenes de expulsión, por lo que estas personas se perpetúan en la condición irregular.

\section{Conclusiones}

Antes de exponer las conclusiones cabe señalar que la complejidad del problema de la relación entre marco normativo y experiencia, en que se sitúa este estudio, requiere de una mayor profundización en torno a las prácticas de las personas migrantes, y en cómo adaptan y adoptan estrategias en su vida cotidiana para saltar las dificultades normativas en el acceso a los derechos. En este sentido, a los ejercicios como el desarrollado aquí, orientados a identificar los "puntos de fuga" que se encuentran en los marcos normativos, tendrían que seguir complementariamente trabajos que busquen en las prácticas institucionales aquellas que puedan incidir en la precarización del acceso a los derechos. Adicionalmente, en una segunda etapa de investigación, resulta necesario abundar más en relación a las singularidades de cada contexto y en la naturaleza de los flujos migratorios, así como en la realidad fronteriza de cada Estado. No es lo mismo "hacer 
frontera" con el país más rico del mundo y principal polo de atracción de migrantes que con países con niveles de desarrollo similar al de origen y con trayectorias históricas de emisión de flujos migratorios.

En un sentido similar, esta primera revisión de los marcos normativos de los dos países seleccionados y las evaluaciones realizadas por la literatura especializada mostró algunos consensos relativos a las condiciones para la pérdida de derechos o para la prolongación del estatus precario o de acceso restringido a la ciudadanía. Sin embargo, cabe señalar que el desarrollo de la investigación en la materia en los dos países es sumamente disímil. En el caso de Canadá, desde fines de la década de 1990 se ha ido construyendo una línea de investigación especializada en las condiciones institucionales de producción del estatus precario. El diagnóstico, por lo tanto, cuenta con mayor desarrollo y complejidad que en Argentina. En este último país, si bien se ha construido un importante cuerpo de análisis sobre la regulación migratoria, las evaluaciones, de carácter crítico la mayoría, apuntan a poner en evidencia la tensión entre la definición de la ley en el marco de los derechos humanos y la dificultad para implementar ese principio en la burocracia estatal.

Este trabajo inicial ha puesto en evidencia también la necesidad de focalizar el estudio no solo en la ley y el sistema de visado/residencia, sino también en la reglamentación complementaria, la normativa administrativa, procedimental, etc., pues en estos instrumentos se encuentran con frecuencia importantes claves de las que dependen muchas veces las trayectorias de los migrantes en torno al acceso a los derechos. Más allá de estas limitaciones e identificación de posibles líneas de trabajo para el futuro, la revisión realizada aquí permite formular algunas conclusiones que consideramos aún en un sentido provisorio.

Una primera conclusión, puesta en evidencia por la literatura canadiense, tiene que ver con el acceso a la información como condición para el acceso a los derechos consagrados en la ley. La situación de los trabajadores temporales en Canadá, por ejemplo, que tienen acceso a derechos de salud, muestra que muchas veces no los ejercen porque no saben que pueden hacerlo. La situación es más grave entre los acompañantes, que también tienen acceso a derechos. En su caso, la información muchas veces depende del titular, que o bien no transmite la información porque no la conoce o la regula como una forma de ejercer control sobre la persona dependiente.

En relación a este último punto, una segunda conclusión del trabajo tiene que ver justamente con la sujeción de los derechos a un tercero, cuestión que se muestra como un nudo crítico en la literatura canadiense. En este sentido se observa que cuando la 
titularidad de derechos de una mujer depende de su pareja hombre, ello puede dar origen a abusos o formas de violencia de género. Estas situaciones, además de un abuso, constituyen una forma de sometimiento a la voluntad del agresor respecto de las posibilidades de acceder autónomamente a la titularidad de los derechos.

Como tercera conclusión, el caso canadiense muestra que los permisos de trabajo temporales que sujetan la titularidad de derechos a la posesión de un contrato de trabajo con un empleador específico, aunque aparentemente son eficaces para la canalización de los flujos de trabajadores migrantes hacia sectores de la economía en que existe una demanda, pueden generar abusos hacia los trabajadores migrantes, toda vez que el acceso a los derechos depende de los empleadores. Este tipo de visado constituye, según la literatura, un instrumento que incentiva la explotación de los trabajadores dependientes, además de un factor de desigualdad respecto de los trabajadores nacionales. Pero, sobre todo, no es posible sujetar el acceso a los derechos a la condición laboral de la persona, un nexo que nos habla de un proceso de unidimensionalización del migrante, en tanto que su presencia solo es legitimada en tanto agente económico, y más específicamente en cuanto trabajador (Sayad, 1998).

Una cuarta conclusión se relaciona con las zonas grises que generan las regulaciones entre posiciones diferenciadas (y jerarquizadas) de ciudadanía (Menjivar, 2006), lo cual es muy evidente en el caso argentino respecto de la situación de ciertos grupos de migrantes extramercosureños, que no logran acreditar sus "propósitos" migratorios en las categorías definidas, y tampoco encuentran en el Estado la intención (no subjetiva) de generar espacios para poner fin a esa situación, a pesar de que la norma ofrece en germen la posibilidad para hacerlo ${ }^{23}$. Sea cual fuere la razón por la que se hubiesen generado esas zonas grises -intenciones, omisiones, imprevisiones, consensos no alcanzados, batallas políticas perdidas o ganadas-, los análisis de la literatura y de los informantes claves muestran que terminan convirtiéndose en instrumentos activos de la política migratoria, definiendo a los migrantes deseables o necesarios y a aquellos que no lo son.

En quinto lugar, la revisión de la literatura referida a los casos canadiense y argentino permite mantener la tesis inicial de este trabajo, en cuanto a que la heterogeneidad de categorías migratorias, aun cuando estén enlazadas entre sí y permitan el tránsito entre ellas, puede abrir espacios para la irregularidad o para el retraso en el acceso a la residencia permanente, perpetuando la condición de temporalidad. El factor crítico en este sentido, identificado tanto por Goldring y Landolt (2013) para Canadá como por Pacecca y

23 Es preciso señalar, sin embargo, que ha habido algunas amnistías para regularizar la situación de algunos de estos grupos de migrantes, pero son recursos excepcionales. 
Courtis (2003) para Argentina, sería la existencia de numerosos procedimientos, "peajes" en palabras de las autoras argentinas, previos a la residencia definitiva. Las renovaciones sucesivas de permisos temporales, condicionadas tanto por procedimientos establecidos -que en ocasiones los migrantes no logran cumplir- como por los costos que implica en términos de trámites -que muchas veces superan los recursos disponibles por los migrantes-, genera un espacio para caer en la irregularidad o entrar en una lógica de "temporalidad permanente". El hecho de no alcanzar la renovación supone no solo una prolongación del proceso, sino en algunas situaciones un retroceso al punto de partida:

En la mayoría de los casos, el migrante debe atravesar una serie de "peajes" -residencia precaria, residencia temporaria, renovación/es de la residencia temporaria- antes de obtener la autorización para residir en forma permanente en el territorio nacional. Por supuesto, cada uno conlleva la presentación de variada y onerosa documentación, así como el pago de las tasas correspondientes, todos ellos gastos significativos y no siempre posibles para la economía del inmigrante. Esto es especialmente crítico porque, por lo general, la no renovación a término devuelve al extranjero a fojas cero, lo cual suele implicar el reinicio del expediente, nuevo pago de tasas, sellados, etc. Este sistema no hace más que retardar y diferir la vinculación legítima del migrante con su lugar de residencia y pone sobre el tapete las dificultades de la administración para concebir a los inmigrantes como sujetos con derecho a gozar de los derechos garantizados por el Estado (Pacceca y Courtis, 2003, p. 14).

Esta observación pone en el centro del problema la tensión entre el cuerpo normativo y las prácticas de los migrantes, pues deja en evidencia que los objetivos que se propone el primero son muchas veces limitados por las consecuencias que significan para las segundas.

En esta misma tensión entre prácticas de los migrantes y cuerpo normativo se encuentra la sexta conclusión de este estudio: la literatura de los dos países evalúa negativamente la existencia de restricciones a las transiciones entre categorías migratorias, y más específicamente entre las visas temporales y las definitivas. La existencia de categorías de permisos de residencia temporal, orientadas a la realización de labores en sectores específicos del mercado de trabajo por períodos de tiempo acotado, implica la creación de incentivos para la migración. Al restringir el tránsito hacia otras categorías o limitar la prórroga que permita la permanencia, se incentiva que aquellos migrantes con voluntad de permanecer o que no encuentran condiciones para regresar a su país de procedencia permanezcan en los países de destino en situación de irregularidad. Asociada a esta situación, aunque no de manera exclusiva, la literatura canadiense identifica una dificultad 
adicional con la existencia de la expulsión como recurso de regulación de las infracciones a la ley migratoria. Los costos y la gestión de las expulsiones superan las capacidades de los Estados para ejecutarlas, con lo que los migrantes que están sujetos a esta sanción permanecen en situación de irregularidad, sin posibilidad de salir de ella por períodos prolongados, quedando expuestos a la vulneración de sus derechos. En este sentido, resulta pertinente revisar no solo el procedimiento relacionado con las expulsiones, sino sobre todo el mecanismo como recurso asociado a las faltas contra la regulación migratoria y a su legitimidad, en tanto que práctica naturalizada de la violencia de Estado (Domenech, 2015).

\section{Referencias}

Acosta, D. y Feline, L. (2015). Turning the Immigration Policy Paradox Upside Down? Populist Liberalism and Discursive Gaps in South America. International Migration Review 49(3), 659-696.

Arango, J. (2004). Las migraciones internacionales en un mundo globalizado. Barcelona: Vanguardia Dossier.

Arat-Koc, S. (1997). From "Mothers of the Nation" to "Migrant workers". En A. Bakan y D. Stasiulis, Not one of family: foreign domestic workers in Canada (pp. 53-79). Toronto: University of Toronto Press.

Basok, T. y Piper, N. (2012). Management versus Rights: Women's Migration and Global Governance in Latin America and the Caribbean. Feminist Economics 18(2), 1-26.

Basok, T. y Carrasco, E. (2010). Advancing the rights of non-citizens in Canada: A Human Rights Approach to Migrant Rights.

Bauböck, R. (2003). Hacia una teoría política del transnacionalismo migrante. Academia Austríaca de Ciencias.

_(2006). Migración y ciudadanía. Zona Abierta 116/117, 135-169.

38 Si Somos Americanos. Revista de Estudios Transfronterizos 
Bernhard, J., Goldring, L., Young, J., Wilson, B. y Berinstein, C. (2008). Living with Precarious Legal Status in Canada: Implications for the Wellbeing of Children and Families. Refuge 24(2), 101-114.

Bloemraad, I. (2016). Becoming a Citizen in the United States and Canada: Structured Mobilization and Immigrant Political Incorporation. Social Forces 85(2), 667-695.

Brubaker, W. R. (1989). Membership Without Citizenship: The Economic and Social Rights of Noncitizens. En W. R. Brubaker (ed.), Immigration and the Politics of Citizenship in Europe and North America (pp.145-161). Nueva York: New York University Press.

Cachón, L. (1989). ¿Movilidad social o trayectorias de clase?: elementos de la sociología de la movilidad social. Madrid: CIS-Siglo XXI.

-_-_ (2010). La España inmigrante: marco discriminatorio, mercado de trabajo y políticas de integración. Barcelona: Anthropos.

Calvita, K. (2007). Law, Immigration and Exclusion in Italy and Spain. Papers 85, 95-108.

Carens, J. H. (2004). La integración de los inmigrantes. En G. Aubarell, y R. Zapata (eds.), Inmigración y procesos de cambio (pp. 393-420). Barcelona: Icaria.

Castles, S. y Miller, M. (1993). La era de la migración. Movimientos internacionales de población en el mundo moderno. México, D.F.: INM-Cámara de Diputados-Fundación Colosio, UAZ-MAP.

Castles, S. y Davidson, A. (2000). Citizenship and Migration: Globalization and the Politics of Belonging. Nueva York: Routledge.

Castles, S. (1995). How Nation States Respond to Immigration and Ethnic Diversity. Journal of Ethnic and Migration Studies 21(3), 293-308.

_-_ - (2003). ¿Adiós al multiculturalismo? Valores e identidades compartidas en las sociedades de inmigración. Revista de Occidente 269, 22-45.

(2006). Factores que hacen y deshacen las políticas migratorias. En A. Portes y J. DeWind, Repensando las migraciones (pp. 33-65). México: Universidad de Zacatecas. 
CELS (Centro de Estudios Legales y Sociales) (2012). Derechos humanos en Argentina: informe 2012. Buenos Aires: Siglo XXI.

- (2016). Informe sobre la Argentina. Situación de los derechos humanos de las personas migrantes. Buenos Aires: Siglo XXI.

Crépeau, F. y Nakache, D. (2006). Controlling Irregular Migration in Canada. Reconciling Security Concerns with Human Rights Protection.

Courtis, C. y Pacecca, M. I. (2007). Migración y derechos humanos: una aproximación crítica al "nuevo paradigma" para el tratamiento de la cuestión migratoria en la Argentina. Revista Jurídica de Buenos Aires, 183-200.

De Génova (2002). Migrant "Illegality" and Deportability in everyday Life. Annual Review of Anthropology 31(1), 419-447.

De Lucas, J. (2007). Inmigración, diversidad cultural, reconocimiento político. Papers 94, 53-77.

DeVoretz, D. J. y Pivnenko, S. (2005). The Economic Causes and Consequences of Canadian Citizenship.

Domenech, E. (2007). El discurso estatal sobre migraciones en la Argentina reciente: de la retórica de la exclusión a la retórica de la inclusión. Trabajo presentado en el III Congreso de la Asociación Latinoamericana de Población, ALAP, realizado en Córdoba, Argentina, del 24 al 26 de septiembre de 2007.

(2009). La visión estatal sobre las migraciones en la Argentina reciente. De la retórica de la exclusión a la retórica de la inclusión. En Migración y política: el Estado interrogado. Procesos actuales en Argentina y Sudamérica. Córdoba: UNC.

(2013). Las migraciones son como el agua: Hacia la instauración de políticas de “control con rostro humano". Polis, Revista Latinoamericana 35, 119-142. Santiago: Universidad de Los Lagos

———— (2015). O controle da imigração “indesejável”: expulsão e expulsabilidade na América do Sul. Ciencia y Cultura 67(2), 25-29.

Ellis, B. (2015). The Production of Irregular Migration in Canada (tesis completa: Deportability and Kombinowanie in Canada: A Critical Ethnographic Study of "Irregular" Migrant Subjectivities). 
Faist, T. y Gredes, J. (2006). La doble ciudadanía como un proceso dependiente de la trayectoria. En A. Portes y J. DeWind, Repensando las migraciones (pp. 97-125). México: Universidad de Zacatecas.

Foucault, M. (1995). Un diálogo sobre el poder y otras conversaciones. Buenos Aires: Alianza.

García, L. (2013). Acceder a derechos a través de puertas giratorias. Derecho humano a migrar y justicia en la Capital Federal a casi diez años de la Ley de Migraciones (25871). XII Jornadas Argentinas de Estudios de Población, Bahía Blanca, 18-20 de septiembre.

Giustiniani, R. (comp.) (2004). Migración: un derecho humano. Ley de Migraciones $N^{\circ} 25.871$. Buenos Aires: Prometeo.

Goldring, L., Berinstein, C. y Bernhard, J. K. (2009). Institutionalizing Precarious Migratory Status in Canada. Citizenship Studies 13, 239-265.

Goldring, L. y Landolt, P. (2012). The Impact of Precarious Legal Status on Immigrants Economic Outcomes. IRPP Study 35, 1-41.

Goldring, L. y Landolt, P. (2013). Producing and Negotiating Non-Citizenship. Precarious Legal Status in Canada. Toronto: University of Toronto Press.

Hammar, T. (1989). Comparing European and North American International Migration. International Migration Review 23(3), 631-637. DOI: 10.2307/2546432.

Kymlicka, W. (1996). Ciudadanía multicultural. Barcelona: Paidós.

Latin American Coalition to End Violence Against Women and Children (2000) No (Wo) Man's Land Report. Toronto: LACEV.

Layton-Henry, Z. (1990). Citizenship or Denizenship for Migrant Workers? En Z. LaytonHenry (ed.), The Political Right of Migrant Workers in Western Europe. Londres: Sage

Lipsky, M. (2010). Street-Level Bureaucracy Dilemmas of the Individual in Public Services. Nueva York: Russell Sage Fundation.

López, A. M. (2005). Inmigrantes y Estados: la respuesta política a la cuestión migratoria. Barcelona: Anthropos. 
Lowry, M. (2002). Creating Human Insecurity: The National Security Focus in Canada's Immigration System. Canada's Journal on Refugees. 21(1), 28-39

Magalhaes, L., Carrasco, C. y Gastaldo, D. (2010). Undocumented Migrants in Canada: A Scope Literature Review on Health, Access to Services and Working Conditions. Journal of Immigrant and Minority Health 12(1), 131-151.

Marshall, T. H. (2001). Ciudadanía y clase social. En T. H. Marshall y T. Bottmore, Ciudadanía $y$ clase social (pp. 15-74). Madrid: Alianza.

Menjivar, C. (2006). Liminal Legality: Salvadoran and Guatemalan Immigrants' Lives in the United States. American Journal of Sociology 111(4), 999-1037.

Menjivar, C. y Abrego, L. (2012). Legal Violence: Immigration Law and Lives on Central American Immigrans. American Journal of Sociology 117(5), 1380-1421.

Mezzadra, S. (2012). Capitalismo, migraciones y luchas sociales. La mirada de la autonomía. Nueva Sociedad 237, 159-178.

Mora, C. (2009). Estratificación social y migración intrarregional: algunas caracterizaciones de la experiencia migratoria en Latinoamérica. Universum 24(1), 128-143.

Nejamkis, L. y Álvarez Nievas, J. (2012). Migración y refugio en la Argentina: un análisis desde la legislación actual. Passagens. Revista Internacional de História Política e Cultura Jurídica 4(3), 445-463.

Novick, S. (ed.) (2008). Las migraciones en América Latina. Políticas, culturas y estrategias. Buenos Aires: Clacso.

_-__ (2010). Políticas migratorias en la Argentina: experiencias del pasado, reformas actuales y expectativas futuras. Mimeo publicado en la página web del Instituto Gino Germani.

OIM (Organización Internacional para las Migraciones) (2012). Perfil migratorio de Argentina 2012. Buenos Aires: OIM.

Pacecca, M. I. y Courtis, C. (2008). Inmigración contemporánea en Argentina: dinámicas y políticas. Serie Población y Desarrollo 84, 1-72. Santiago: CEPAL. 
Portes, A. y Böröcz, J. (1989). Contemporary Immigration: Theoretical Perspectivas on its Determinants and Modes of Incorporation. International Migration Review 23, 606-630.

Portes, A. y Rumbaut, R. (1990). Immigrant America: A Portrait. Los Angeles: University of California Press.

Portes, A. y DeWind, J. (2006). Un diálogo transatlántico: el progreso de la investigación y la teoría en el estudio de la migración internacional. En A. Portes y J. DeWind, Repensando las migraciones (pp. 7-27). México: Universidad de Zacatecas.

Preibisch, K. (2004). Migrant Agricultural Workers and Processes of Social Inclusion in Rural Canada: Encuentros and Desencuentros. Canadian Journal of Latin American and Caribbean Studies 29(57), 203-239.

Rajkumar, D., Berkowitz, L., Vosko, L. F., Preston, V. y Latham, R. (2012). At the TemporaryPermanent Divide: How Canada Produces Temporariness and Makes Citizens through its Security, Work, and Settlement Policies. Citizenship Studies 16(3-4).

Sassen, S. (2010). Territorio, autoridad y derechos. De los ensamblajes medievales a los ensamblajes globales. Buenos Aires: Katz.

Sayad, A. (1998). A Imigração ou os Paradoxos da Alteridades. São Paulo: Editora da Universidade de São Paulo.

Simmons, A. B. (2010). Immigration in Canada, Global and Transnational Perspectives. Toronto: Canadian Scholar's Press Inc.

Solé, C. (2000). Derechos y deberes frente al racismo y a la integración de los inmigrantes en la sociedad receptora. Sociedad y Utopía 16, 119-132.

Weil, P. y Crowley, J. (1994). Integration in Theory and Practice: A Comparison of France and Britain. West European Politics 17(2), 110-126.

Wright, C. (2013). The Museum of Illegal Immigration: Historical Perspectives on the Production of Non-Citizens and Challenges to Immigration Controls. En L. Goldring y P. Landolt, Producing and Negotiating Non-Citizenship. Precarious Legal Status in Canada (pp. 31-54). Toronto: University of Toronto Press.

Zapata, R. (2009). Fundamentos de los discursos políticos en torno a la inmigración. Madrid: Trotta. 